\title{
Selected Plant Extracts Show Antiviral Effects against Murine Norovirus Surrogate
}

\author{
Uchenna Iloghalu1,2, Bryce Holmes ${ }^{1}$, Janak Khatiwada',2, Leonard L. Williams, ${ }^{1,2}$ \\ ${ }^{1}$ North Carolina A\&T State University, Greensboro, USA \\ ${ }^{2}$ Center for Excellence in Post-Harvest Technologies, Kannapolis, USA \\ Email: ^1lw@ncat.edu
}

How to cite this paper: Iloghalu, U., Holmes, B., Khatiwada, J. and Williams, L.L. (2019) Selected Plant Extracts Show Antiviral Effects against Murine Norovirus Surrogate. Advances in Microbiology, 9, 372-384.

https://doi.org/10.4236/aim.2019.94022

Received: January 29, 2019

Accepted: April 22, 2019

Published: April 25, 2019

Copyright $\odot 2019$ by author(s) and Scientific Research Publishing Inc. This work is licensed under the Creative Commons Attribution International License (CC BY 4.0).

http://creativecommons.org/licenses/by/4.0/ (c) (i) Open Access

\begin{abstract}
Noroviruses are the most common cause of acute gastroenteritis. Annually, 21 million Americans are infected with norovirus. Recent advances in molecular diagnostics have helped to establish norovirus as the most common cause of outbreaks of acute gastroenteritis across all ages. However, there is no effective or efficient treatment/control against norovirus infection. Conventional intervention techniques used to inactivate norovirus have shown lack of efficacy against human norovirus. Currently, effective treatment or control measures against human norovirus have not been identified. In this study, murine norovirus acts as a model to human norovirus to evaluate the inhibitory effects of crude extracts of Zanthoxylum armatum and Hibiscus sabdariffa. The study also separated, identified and quantified the selected compounds using the ultra-liquid chromatography (UPLC). To study the antiviral activities of crude extracts and its fractionated portions of $Z$. armatum and $H$. sabdariffa against norovirus surrogate, RAW 264.7 cells were infected with Murine norovirus surrogate virus of human norovirus and incubated at $37^{\circ} \mathrm{C}$. Phytochemicals were extracted from the seeds and calyces of the plants using methanolic extraction. Fractionated portions of the crude extracts were subsequently used in both chromatographic and microbiological studies. Our data indicated that there was reduction of viruses, when treated with the $60 \%$ aqueous methanol extracts. Amongst the four selected phenolic compounds (myricetin, quercetin, kaempferol and luteolin), quercetin showed the most significant logarithmic viral reductions. These compounds were identified, purified and quantified using UPLC. Extracts of Zanthoxylum armatum and $\mathrm{Hi}$ biscus sabdariffa showed antiviral effects. Phenolic compounds are virucidal. Extracts of Hibiscus sabdariffa also exhibits anti-norovirus activities. The results are anticipated to control/prevent the human norovirus infections.
\end{abstract}

\section{Keywords}

Plant Extracts, Fractionation, Noroviruses, Plaque Assay 


\section{Introduction}

Human norovirus (HuNoVs) infection which was once mild [1] has taken the lead in the cause of pervasive diarrheal disease among all human race especially the immune-compromised. This characteristic is mostly because the virus contains all the properties of an archetype infectious agent: continuously evolving, inducing reduced immunity, extremely contagious, relatively virulent and abundantly shed, hence maintaining a large vulnerable group of hosts [2]. The virus low transmissible dose permits it to spread quickly between person-to-person [3]. Fomites, droplets and environmental surfaces are also sources of norovirus contamination. The virus can tolerate a broad temperature range from freezing to $60^{\circ} \mathrm{C}$ and mostly, survive on environmental surfaces [4].

HuNoVs causes acute gastroenteritis of nonbacterial origin common in the western world. Research finding has confirmed norovirus as the causal agent for human gastroenteritis [5]. Absence of routine diagnostic laboratory techniques have been hindering in depth study of this group of viruses [5]. Culturing human norovirus is extremely challenging and expensive. Although a group of scientists has tried culturing human noroviruses using human enterocytes in stem cell-derived, non-transformed human intestinal enteroid monolayer cultures [2], the ease of cultivation remains elusive. Cultivable surrogates like murine norovirus (MNV-1) and feline calicivirus (FCV-F9) are currently used as human norovirus surrogates [6]. MNV-1 has been widely accepted as the ultimate proxy which mimics the inactivation and survival of human norovirus [7]. Currently, effective treatment or control measures against human norovirus have not been identified. This study uses the murine norovirus as a model to human norovirus to evaluate the effect of Myricetin, Quercetin, Kaempferol, and Luteolin on norovirus surrogate.

Flavonoids have been shown to be rich in antioxidants, anti-inflammatory, antidiarrheal, antimicrobial, antiallergic, antidiabetic and antihepatotoxic properties [8]. Flavonoids are an assorted group of phytochemicals available in almost all vegetables and fruits. They are mostly responsible for brilliant colors in plants [9], and more than 4000 types abound [10]. Many of these flavonoids have been documented to be effective against RNA viruses which include the non-enveloped viruses typically the Caliciviridae group [11]. The health benefits of this group of phytochemicals have placed it in the forefront for scientific studies.

Various techniques like plaque assay (quantitative), transmission electron microscope (qualitative), fractionation, and ultra-performance liquid chromatography (UPLC) were adopted in the study. Methanoic extraction was used in extracting phytochemicals from the plants Hibiscus sabdariffa (HS) and Zanthoxylum armatum (ZA). Fractionated portions of the crude extracts were subsequently used in both chromatographic and microbiological studies.

Hibiscus sabdariffa (calyces)

Hibiscus sabdariffa is extensively grown in the Caribbean and identified as 
sorrel. It possesses a broad range of applications including antibacterial, antifungal, hypo cholesteric, diuretic, mild laxative, uricosuric and antihypertensive qualities. The powdered dried calyx extracts are used as diet nourishment [12]. It has been demonstrated that aqueous extract of the plant possesses antiviral effect on human norovirus surrogates feline calicivirus-9 (FCV-F9) and murine norovirus (MNV-1) as well as in hepatitis A virus [13]. Hibiscus sabdariffa possesses antioxidant, anti-diabetic and antimicrobial properties [13]. Hibiscus sabdariffa has been confirmed to be rich in phenolic acids, flavonoids, and anthocyanins [13]. Given the potentials of this plant, its effect against the murine norovirus was studied.

\section{Zanthoxylum armatum}

Zanthoxylum armatum belongs to the Rutaceae family and has an extensive medicinal use. It is traditionally known to have different names for the various countries. For instance, in Nepal it is known as toothache tree or Nepal pepper; in India where it is abundantly spread, it is known as Indian Prickly Ash. Zanthoxylum armatum also grows well in China, Malaysia, Philippines, Taiwan, Japan and Pakistan. Folk medicine believes this plant to be effective against a host of medical conditions. Amongst them are anthelmintic, stomachic, and carminative. Both the fruits and seeds offer controlling effects for fever and dyspepsia. It is also known to harbor phytochemicals like phenolics, lignin, sterols, coumarins, terpenoids, flavonoids and their glycosides, fatty acids, alkenoic acids and amino acids [14].

Phytochemicals in Hibiscus sabdariffa and Zanthoxylum armatum and their health benefits

Phytochemical profile of $H$. sabdariffa has previously studied and shown that phenolic compounds, flavonoids and anthocyanin [15] [16] amongst others were present. Phenolics or simply, phenols are a class of chemical compounds made up of hydroxyl group directly bonded to an aromatic hydrocarbon group. Phenolic compounds classified as simple or polyphenols based on the amount of phenol units present in the molecule [16] [17].

Flavonoids are natural plant pigments produced from phenylalanine and mostly responsible for distinct colors in plants. The anthocyanins are responsible for the red color pigmentation in most plants, and they are abundant in plants. Flavonoids are members of polyphenols with 15 carbon atoms and are soluble in water. Flavonoids are of six main subtypes: flavones, anthocyanins, anthoxanthins, chalcones, isoflavonoids, and flavanones. They are pigment producers. Hence, flavonoids are critical in color production in plants [18]. These produced color assist in attracting insects for pollination. Flavonoids aids in nitrogen fixation, UV filtration, cell cycle inhibition and as chemical messengers.

Flavonoids are essential antioxidants [19] and are antiviral, anticancer, anti-inflammatory and anti-allergic [18]. Studies have shown that flavonoids have demonstrated a protective effect against cardiovascular diseases. Environmental factors example light, species, and post-harvest management influence the level of flavonoids found in foods [18]. 


\section{Materials and Methods}

\section{Human norovirus surrogate and RAW 264.7 cell}

RAW 264.7 cells (ATCC TIB-71) (ATCC Manassas, VA) and murine norovirus (MNV-1 CW1), purchased from ATCC were used throughout the experiment. The cell line was activated in complete Dulbecco's Minimum Essential Medium containing 10\% low endotoxin fetal bovine serum (Gibco, Manassas, VA USA), and Penicillin Streptomycin, with (-) 5000 units/ml Penicillin and (-) $5000 \mu \mathrm{g} / \mathrm{ml}$ Streptomycin was used to reduce contamination. Cells were activated into a T-75 $\mathrm{cm}^{2}$ flask and approximately $90 \%$ confluency was reached within 48 hours. The cells were transferred to six-well plates at $81 \%$ live cells, allowed to incubate for 24 hours in $5 \% \mathrm{CO}_{2}$ in incubator. Prior to viral infection, all media was aspirated and $500 \mathrm{ul}$ of earlier made viral stock $\left(10^{-4}\right)$ with media was added into the flask and incubated for two hours in a humidified incubator at $37^{\circ} \mathrm{C}$ in $5 \% \mathrm{CO}_{2}$. Flasks were swayed gently every 15 minutes to enhance uniform viral distribution. The virus was aspirated at the end of incubation. Following aspiration, low-melting agarose and $2 \times$ minimum essential medium (Gibco, Rockville, MD, USA), supplemented with $20 \%$ fetal bovine serum was added to the flask and incubated at $37^{\circ} \mathrm{C}$ in $5 \% \mathrm{CO}_{2}$ for 72 hours. The experiment was repeated thrice. The cells were stained with neutral red in PBS and viewed under the microscope.

\section{Plants extracts}

Fresh calyces of Hibiscus sabdariffa (HS) were obtained from the North Carolina Agricultural and Technical State's farm and seeds of Zanthoxylum armatum (ZA) were purchased from a local vendor.

Extraction process for Hibiscus sabdariffa (calyces) and Zanthoxylum armatum (seeds)

Approximately 15 grams of each of the previously dried and ground plant materials was extracted using the Miean and Mohamed methods [20]. Thereafter, $312.5 \mathrm{ml}$ of methanol and $187.5 \mathrm{ml}$ distilled water (both amounted to about 500 by volume) mixed. Approximately, $1 \mathrm{~g} / 500 \mathrm{~L}$ TBHQ added to the mixture and $125 \mathrm{ml}$ of $6 \mathrm{M} \mathrm{HCl}$ was added to the aqueous methanol (HPLC grade). The mixture was then vortexed and refluxed at $90^{\circ} \mathrm{C}$ for 2 hours. The extracts were cooled and filtered with Buchner filter. The filtrate was made up to $50 \mathrm{ml}$ with methanol. The methanol-filtrate was re-filtered and sterilized using $0.45 \mu \mathrm{m}$ membrane filter. The extracts were stored in airtight bottles wrapped with foil and kept at $-20^{\circ} \mathrm{C}$ until analyzed.

\section{Drying and concentration of extracts}

About $10 \mathrm{ml}$ of each of the extract was placed in a small round-bottomed flask and subjected to a rotary evaporator for efficient and gentle removal of solvent from the solution. The evaporation continued until the appearance of solute. The solute was re-dissolved using very small quantity of $100 \%$ methanol concentration to ensure complete removal of water. Complete water removal was enhanced by maintaining the rotavap temperature at $47^{\circ} \mathrm{C}$ and use of mild 
stream of nitrogen under a hood. It was then transferred to a tube and thoroughly dried using reacti-Vap evaporator. This system evaporates samples with ease and efficiently by delivering pressurized gas to samples in the Reacti-Therm module. Approximately $200 \mathrm{mg} / \mathrm{ml}$ of each of the extract was used in subsequent experiments.

Ultra Performance Liquid Chromatography (UPLC) analysis of the crude extract

The method employed by Miean K. H and Mohamed Suhaila (2001) with slight modifications was used. The crude extracts of both plants were quantified using the Waters UPLC $\mathrm{H}$ Class with Photodiode array detector (PDA) UV at $365 \mathrm{~nm}$ at flow rate of $0.700 \mathrm{ml} / \mathrm{min}$. The injection volume was $1.0 \mu \mathrm{l}$ and the column type was Waters Atlantis Hilic Silic column, with particle size $3.0 \mathrm{mi}$ crons, $2.1 \mathrm{~mm}$ internal diameter, $100 \mathrm{~mm}$ long. Retention time of the respective standard was used to identify the compounds of interest. Chromatograms from the crude were compared with those of the standard chromatograms.

Four important flavonoids compounds (myricetin, quercetin, luteolin and kaempferol) were selected based on the antimicrobial properties associated with the individual flavonoids compound. They are mainly known to be an excellent source of antioxidant, anti-inflammatory and antimicrobial. The crude extracts were further diluted 20 times with methanol/water (50:50 v/v) solvent.

\section{Transmission Electron Microscopy (TEM)}

TEM imaging was performed to discern rightly possible underlying changes to the MNV after exposure to treatment conditions with HS and ZA. The samples were fixed with $2 \%$ formaldehyde in buffer. The fixation reagent covers the surfaces of the samples. This was incubated for about 30 minutes at room temperature and each of the samples was carefully washed three times with buffer and each wash lasting for about 3 minutes and sealed with Para film. The sample suspensions were placed in a microfuge and freeze-thawed. The essence of freeze-thaw was to release more viruses in the medium, even though the studied virus was a naked virus and icosahedral in shape.

Approximately, $10 \mu \mathrm{l}$ of each of the treated and untreated samples from the 72-h incubation was exposed to different conditions (Neat, freeze-thaw, ultra-freeze-thaw) and was separately placed on the grids. Further, large particles such as cell debris and bacteria were spun down at a low speed $(\sim 3000 \times \mathrm{g})$ for 3 minutes. The supernatant was placed right onto a grid and negatively stained. About $2 \mathrm{ml}$ of sample was ultra-centrifuged $(100,000 \times \mathrm{g})$ using the benchtop ultra-centrifuge for about 50 minutes.

\section{Negative staining}

Two percent uranyl acetate was placed dropwise beside each of the grid samples. The hydrophilic support film with freshly carbon-coated grid enhances proper distribution of the sample. The grids were stabilized by vaporizing a thin carbon coat over them to keep them from dissolving in the electron beam and sustain conductivity. The grids were initially treated with a drop of $1 \%$ aqueous Alcian blue for 5 minutes. This was prepared just prior to adsorption of virus 
[21]. The samples were washed, drained and covered with petri dish for about two minutes.

\section{Statistical analyses}

Data were analyzed using student t-test (Graph pad Prism software version $7.0)$ to determine the significance $(\mathrm{p}<0.05)$ between the treated and control groups.

\section{Results and Discussions}

\section{Quantification of virus}

The main objective was to determine the optimal dilutions of the virus required for viral plaque formation. Briefly, 9-fold serial dilutions of $\mathrm{MNV}-1$ in DMEM-10 was grown in an exponentially growing RAW 264.7 monolayer. Neutral red diluted with PBS ( $\mathrm{pH}$ 7.4) was used in briefly staining the monolayer. Plaques were counted. The number of plaques gradually increases until it reaches optimum at $10^{-4}$ dilution and then started to decrease (Figure 1). The results showed that there was more plaques formation from $10^{-4}$ dilution. Therefore, $10^{-4}$ dilution of MNV was selected for further study.

Treatment of infected cell line with crude extracts

The effect of the crude extracts of the two plants namely Hibiscus sabdariffa (calyces) and Zanthoxylum armatum (seeds) on human norovirus surrogate was studied. The calyces and seeds were washed, freeze-dried and mechanically ground to powder. The finely-powdered material was then vortexed and refluxed at $90^{\circ} \mathrm{C}$ for 2 hours using acidified methanol. Extracts were concentrated using rotary evaporator and liquid nitrogen. Approximately, $200 \mathrm{mg} / \mathrm{ml}$ of each extract with varying concentrations $(2.5 \%, 5 \%$, and $10 \%)$ was used in treating the virusinfected cells (Figure 2). Result has shown that Zanthoxylum armatum's seed extract showed significant viral log reduction with $10 \%$ concentration (Figure 2) compare to control. Although all the treatment groups showed a noticeable viral reduction, 10\% Zanthoxylum armatum exhibited the best viral activity. Our data indicate that the viral reduction is significant $(\mathrm{P}<0.05)$ compared with control.

Transmission electron microscopy (TEM) imaging

Three cultures with different conditions: Infected cells with no extract (A), infected cells with crude extract ZA (B), and HS (C) were studied (Figure 3 and Figure 4). Our result showed presence of viruses by negative stain (NS) and electron microscopy (EM) exhibited in the different conditions. The frozen and thawed showed presence of virus particles. Further ultracentrifugation of the three cultures shows the apparent presence of viruses by both the NS and EM. The result showed no significant differences in the ultrastructure of the viruses.

Qualitative optimization of conditions for murine norovirus treatment

We optimized varying conditions to find out the difference in the viral reduction from each unique experiment. We discovered that the treated $\mathrm{C}$ and $\mathrm{D}$ showed reductions in the number of virus per field of microscope, (with crude ZA showing more viral reduction). This qualitative test confirms our initial results obtained from quantitative studies. 


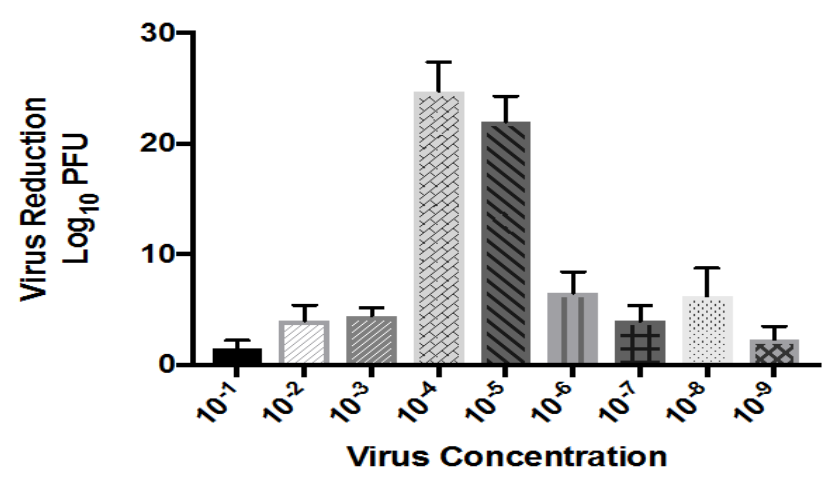

Figure 1. A plot representation of the plaque assay quantification (viral infectivity). $\log _{10}$ PFU (copy number of MNV-1) plotted against serially diluted virus concentrations. Error bars, standard errors of the means (Graph pad prism 7) from three independent experiments.

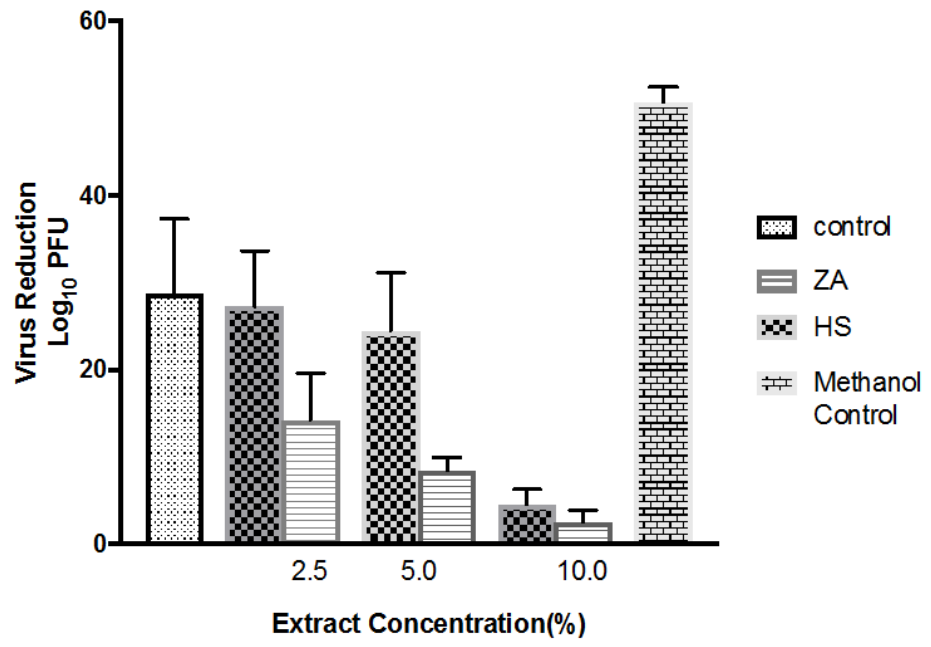

Figure 2. Antiviral activities of methanol extracts of Zanthoxylum armatum (seeds) and Hibiscus sabdariffa (calyces) on murine norovirus (MNV-1). Metcon is the methanol control. Error bars denote standard deviations from three replicate assays.

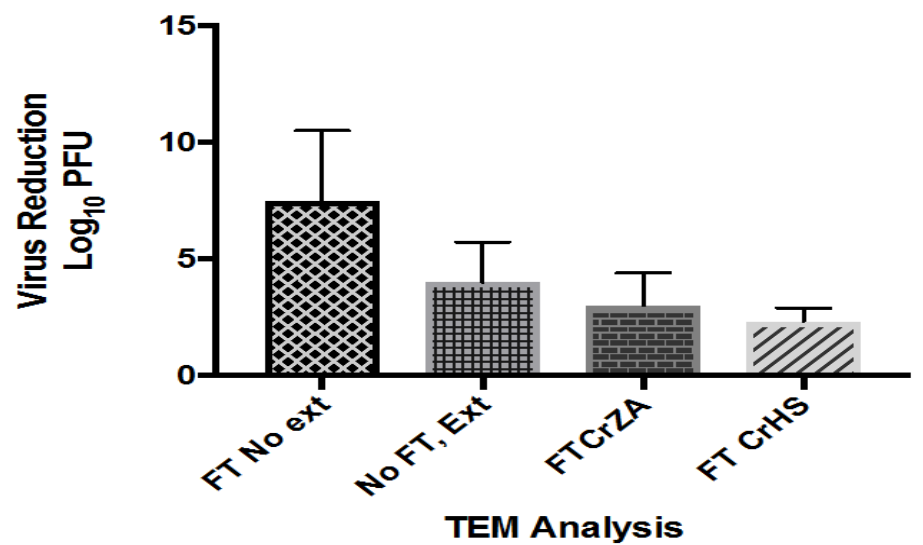

Figure 3. Transmission electron microscopy observation for MNV-1 (L-R: Freeze-thaw no extract; Extract no freeze-thaw, freeze-thaw crude ZA and freeze-thaw crude HS). The incubation lasted for three days in a humidified incubator at $37^{\circ} \mathrm{C}$ at $5 \% \mathrm{CO}_{2}$. 


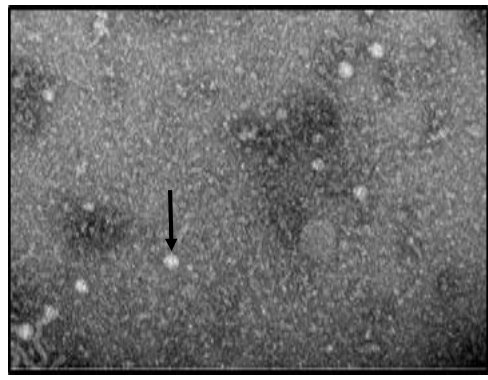

(a)

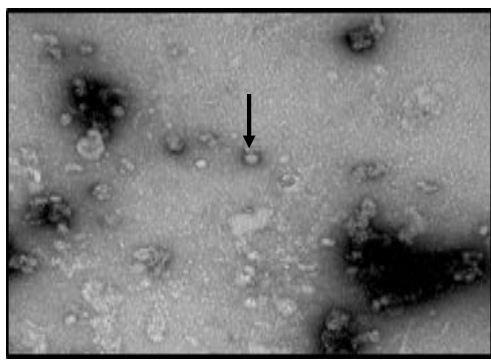

(c)

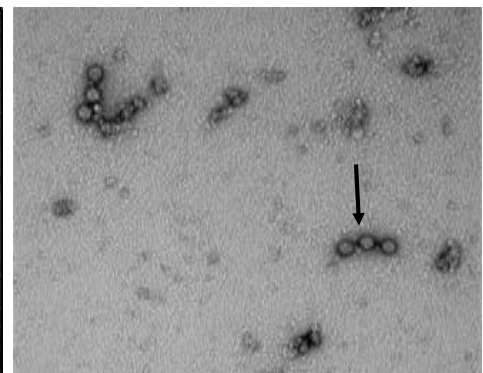

(b)

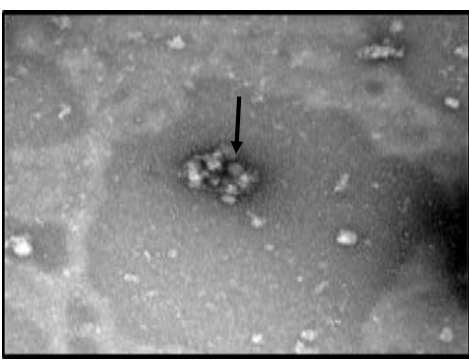

(d)

Figure 4. Transmission electron microscope micrographs of MNV (Murine norovirus). Freeze-thaw untreated $\mathrm{MNV}$ (a). Neat (unmixed) untreated MNV (b), Treated with crude ZA (c) and treated with crude HS (d).

Ultra-performance Liquid Chromatography of calyces of Hibiscus sabdariffa and seeds of Zanthoxylum armatum

We optimized samples separation, quantification, and identification using retention times of the different flavonoids standards. Flavonoids (Quercetin, Myricetin, Kaempferol, and Luteolin) were identified from both crude and fractionated portions of the extract. The chromatographic conditions using 50/50 methanol water mobile phase was set based on isocratic method. The crude sample was diluted to about $0.5 / 10 \mathrm{ml}$ methanol due to an initial high concentration of the samples. Crude extracts of Hibiscus sabdariffa and Zanthoxylum armatum were diluted up to 20 times to obtain working level, whereas the fractionated ones (hexane, ethyl acetate, butanol and water parts) were only reduced twice to achieve the uniform concentration.

The injection volume of each of the compound was $1.0 \mu$ with flow rate of $0.700 \mathrm{ml} /$ minute, and the internal temperature remains $-33^{\circ} \mathrm{C}$ and PDA detector was $395 \mathrm{~nm}$. The results are shown below.

\section{Screening of flavonoids content}

Analysis of four types of flavonoids, namely myricetin, quercetin, kaempferol and luteolin, in methanol extracts of crude Zanthoxylum armatum, Hibiscus sabdariffa and their fractionated fractions were shown in Table 1. Among the two plant extracts and their fractionated portions, only luteolin showed below quantitation detection limit. Crude ZA showed no presence of myricetin, and surprisingly, hexane fraction of HS indicated $684 \mathrm{mg} / \mathrm{kg}$ of flavonoids. The results noticeably suggested that both crude and fractionated portions contain varying amounts of flavonoids compounds. 
Table 1. Flavonoids Analysis of crude Zanthoxylum armatum, Hibiscus sabdariffa and Fractionated Portions of both Plants in $\mathrm{Mg} / \mathrm{kg}$.

\begin{tabular}{ccccc}
\hline SampleID & Myricetin & Quercetin & Luteolin & Kaempferol \\
\hline HFH & 684 & 2052 & BQDL & 102.6 \\
EAFH & BQDL & BQDL & BQDL & BQDL \\
WFH & BQDL & BQDL & BQDL & BQDL \\
BFH & BQDL & BQDL & BQDL & BQDL \\
HFZ & BQDL & 2428.2 & BQDL & 171 \\
EAFZ & BQDL & 3112.2 & BQDL & 205.2 \\
BFZ & BQDL & BQDL & BQDL & BQDL \\
WFZ & BQDL & BQDL & BQDL & BQDL \\
Crude HS & BQDL & 28,728 & BQDL & 1026 \\
Crude ZA & BQDL & 94,392 & BQDL & 9576 \\
\hline
\end{tabular}

Key: $\mathbf{H F H}=$ Hexane Fraction HS; EAFH = Ethyl Acetate Fraction HS; WFH = Water Fraction HS; $\mathbf{B F H}=$ Butanol Fraction HS; HFZ = Hexane Fraction ZA; EAFZ = Ethyl Acetate Fraction ZA; BFZ = Butanol Fraction ZA; WFZ = Water Fraction ZA; BQDL = Below Quantitation Detection Limit.

No information of the flavonoid contents of the calyces and seeds and their fractionated portions examined in this research have not previously been documented. Rhu et al. [22] reiterated that previous studies have confirmed polyphenols and flavonoids as bioactive compounds that are effective against norovirus infection. Previous studies have equally documented that methanol enhances the extraction of flavonoids which in turn yield varying amounts of flavonoids compounds [20]. The quercetin content of crude ZA $(94,392 \mathrm{mg} / \mathrm{kg}$ ) was significantly higher than that of crude HS $(28,728 \mathrm{mg} / \mathrm{kg}$ ) (Table 1). Our studies show that kaempferol was moderately available in the crude ZA (9576 $\mathrm{mg} / \mathrm{kg})$, whereas HS had $(1026 \mathrm{mg} / \mathrm{kg})$. Interestingly, both myricetin and luteolin contents in both crude ZA and HS were below detection limits. It was more interesting to find out that although myricetin content of the two crude extracts was not within detection limit in both crudes, hexane fraction of HS excitingly indicated $684 \mathrm{mg} / \mathrm{kg}$ of myricetin (Table 1). The myricetin present in hexane fraction of HS shows that hexane can extract valuable bioactive compounds which were previously elusive.

\section{Discussion}

Norovirus is a contagious virus that causes gastrointestinal illnesses in humans. Currently, effective treatment or control measures against human norovirus have not been identified. This study uses the murine norovirus as a model to human norovirus to evaluate the effect of Myricetin, Quercetin, Kaempferol, and Luteolin on norovirus surrogate. Myricetin, Quercetin, Kaempferol and Luteolin are flavonoids of interest due to their established antimicrobial, anti-inflammatory, antioxidants, antidiarrheal, antiallergic, antidiabetic and antihepatotoxic properties [8]. Amongst the serially diluted virus, $10^{-4}$ showed more plaque for- 
mations and was selected for further studies. Following methanoic extraction of the studied plants, it was observed that ZA (seed) showed significant viral log reduction. Both plant extracts were separated, quantified and identified using the ultra-performance liquid chromatography (UPLC). It was observed that both crude and fractionated portions contain varying amounts of flavonoids compounds. We noticed that hexane fraction of HS showed presence of myricetin from which was previously elusive in the crude fraction. In our study, we discovered that the treated ethyl acetate and butanol fractions showed reductions in the number of virus per field of microscope, with crude ZA showing more viral reduction compared to crude HS. This qualitative test confirms our initial results obtained from quantitative studies. Further ultracentrifugation of the three cultures shows the apparent presence of viruses by both the negative staining and electron microscope. The result showed no significant differences in the ultrastructure of the viruses.

Many factors such as incubation temperature [23], viability of cell line [24] antibiotics, [25] influence the plaque formation. In this study, we observed that amongst the serially diluted virus, $10^{-4}$ showed more plaque formations. As the dilution increases, the number of viral particles present in the given dilution reduces and this leads to a point where the amount of virus present leads to plaque formation detection [26]. $10^{-4}$ dilution is the best dilution for the plaque formation and was selected for subsequent experiments.

An equal ratio of methanol/water composition was used as the mobile phase, and the chromatographic conditions were established based on the isocratic method for compounds separation. The separations and identifications of the compounds relied primarily on retention times of the crude extracts and their fractionated fractions (hexane, ethyl acetate, butanol, and water parts). The flavonoids standard retention times are 1.39, 2.181, 2.558 and 3.564 (minutes) for myricetin, quercetin, kaempferol and luteolin respectively, and the crude portions of Zanthoxylum armatum (ZA) had its retention times at 2.503 (Kaempferol) and 4.216 (another compound not included in the study), whereas the retention times of Hibiscus sabdariffa are 2.194 (Quercetin) and 4.214 (another polyphenolic compound not included in the study) (Data not shown here). These compounds not identified here are inseparable from the known ones hence synergistic effect could have played a role in achieving antiviral effects. These inherent flavonoids may have also contributed to the synergistic effect of the selected flavonoids in plaque reduction. In Table 1, crude ZA showed the highest amount of quercetin $(94,392 \mathrm{mg} / \mathrm{kg})$, followed closely by crude HS $(28,728 \mathrm{mg} / \mathrm{kg})$, crude ZA kaempferol $(9576 \mathrm{mg} / \mathrm{kg}$ ) and crude HS kaempferol (1026 mg/kg). Those that read below the quantitative detection limit (BQDL) were considered $>10 \mathrm{mg} / \mathrm{kg}$. The variations in the quantity of an extracted flavonoids could be attributed to the amount of the selected flavonoids present in the calyces or seeds of the studied plants (Table 1).

The fractionated portions of the extracts showed hexane fractions yielded 
quercetin $2428.2 \mathrm{mg} / \mathrm{kg}$ (ZA) and $2052 \mathrm{mg} / \mathrm{kg}$ (HS) respectively; kaempferol 171 $\mathrm{mg} / \mathrm{kg}(\mathrm{ZA})$, and $102.6 \mathrm{mg} / \mathrm{kg}$ respectively. Hexane compound have indicated the highest ability to extract flavonoids in both plants (Table 1). Interestingly, myricetin $(684 \mathrm{mg} / \mathrm{kg})$ was only present in the hexane fraction of HS.

The result of different concentrations of the crude extracts $(10 \%, 5 \%$, and $2.5 \%)$ reflected the presence of antiviral bioactive compounds present in the extracts (Figure 2). Our result showed that $10 \%$ of both extracts indicated high viral reductions with $10 \% \mathrm{ZA}$ outstandingly showing the best antiviral activities. This viral reduction could be attributed to greater amount of quercetin present in crude ZA $(94,392 \mathrm{mg} / \mathrm{kg})$. Culture of flavonoids standards showed that quercetin had the most outstanding effects when compared with the other studied flavonoids standards.

- Flavonoids are phenolic compounds that are commonly found in plants. Research has shown that:

- Flavonoids are antiviral [8] [27]. The results evidently showed that the tested extracts were rich in these selected flavonoids, and the qualities and quantities of the chosen flavonoids in these extracts seemed to be very different among the crude and fractionated portions [20]. The major flavonoid that was found to reduce the number of plaques is the flavonol Quercetin, followed by Kaempferol, Luteolin and Myricetin. In a similar study, quercetin exhibited anti-Japanese encephalitis virus activity when used against JEV adsorption to the cells. It was also demonstrated that the production of JEV-RNA decreased more than $17 \%$ in the presence of $50 \mu \mathrm{g} / \mathrm{mL}$ of quercetin when it was used after virus adsorption [28].

\section{Acknowledgements}

This research was financially supported in part by Agriculture and Food Research Initiative grant No. 2011-6800-30395 from the USDA National Institute of Food and Agriculture through the NoroCORE project. The authors thank Prof Sarah Miller and John Carter whose contributions cannot be quantified.

\section{Conflicts of Interest}

The authors declare no conflicts of interest regarding the publication of this paper.

\section{References}

[1] Shuichi, I., Takeshita, S., Nezu, A., et al. (2006) Norovirus-Associated Encephalopathy. The Pediatric Infectious Disease Journal, 25, 651-652. https://doi.org/10.1097/01.inf.0000225789.92512.6d

[2] Khalil, E., Crawford, S.E., Murakami, K., et al. (2016) Replication of Human Noroviruses in Stem Cell-Derived Human Enteroids. Science, 353, 1387-1393.

[3] Hall, A.J., Vinjé, J., Lopman, B., Park, G.W., Yen, C., Gregoricus, N. and Parashar, U. (2011) Updated Norovirus Outbreak Management and Disease Prevention Guidelines. Morbidity and Mortality Weekly Report. Recommendations and Re- 
ports, 60, 1-15.

[4] Idrissa, S., Hammami, R., Rayas, R.M., Fliss, I. and Jean, J. (2015) Stability of Secondary and Tertiary Structures of Virus-Like Particles Representing Noroviruses GI. 1 and GII. 4 and Feline Calicivirus: Effects of pH, Ionic Strength and Temperature and Implications for Adhesion to Surfaces. Applied and Environmental Microbiology, 81, 7680-7686.

[5] Glass, R.I., Parashar, U.D. and Estes, M.K. (2009) Norovirus Gastroenteritis. New England Journal of Medicine, 361, 1776-1785. https://doi.org/10.1056/NEJMra0804575

[6] Bozkurt, H., Leiser, S., Davidson, P.M. and D'Souza, D.H. (2014) Thermal Inactivation Kinetic Modeling of Human Norovirus Surrogates in Blue Mussel (Mytilus edulis) Homogenate. International Journal of Food Microbiology, 172, 130-136. https://doi.org/10.1016/j.ijfoodmicro.2013.11.026

[7] Tung, G., Macinga, D., Arbogast, J. and Jaykus, L.-A. (2013) Efficacy of Commonly Used Disinfectants for Inactivation of Human Noroviruses and Their Surrogates. Journal of Food Protection, 76, 1210-1217. https://doi.org/10.4315/0362-028X.JFP-12-532

[8] Joo, S.D., Jeon, S.B., Oh, H., et al. (2016) Comparison of the Antiviral Activity of Flavonoids against Murine Norovirus and Feline Calicivirus. Food Control, 60, 25-30. https://doi.org/10.1016/j.foodcont.2015.07.023

[9] Tan, J., Wang, M., Tu, L., et al. (2013) The Flavonoid Pathway Regulates the Petal Colors of Cotton Flower. PLOS ONE, 8, e72364.

https://doi.org/10.1371/journal.pone.0072364

[10] Cheynier, V. (2005) Polyphenols in Foods Are More Complex than Often Thought. The American Journal of Clinical Nutrition, 81, 223S-229S. https://doi.org/10.1093/ajcn/81.1.223S

[11] Raj, U. and Varadwaj, P.K. (2016) Flavonoids as Multi-Target Inhibitors for Proteins Associated with Ebola Virus: In Silico Discovery Using Virtual Screening and Molecular Docking Studies. Interdisciplinary Sciences. Computational Life Sciences, 8, 132-141. https://doi.org/10.1007/s12539-015-0109-8

[12] Vilasinee, H., Utaipat, A., Morales, N.P., et al. (2006) Hypocholesterolemic and Antioxidant Effects of Aqueous Extracts from the Dried Calyx of Hibiscus sabdariffa L. in Hypercholesterolemic Rats. Journal of Ethnopharmacology, 103, 252-260. https://doi.org/10.1016/j.jep.2005.08.033

[13] Joshi, S.S., Dice, L. and D’Souza, D.H. (2015) Aqueous Extracts of Hibiscus sabdariffa Calyces Decrease Hepatitis A Virus and Human Norovirus Surrogate Titers. Food and Environmental Virology, 7, 366-373. https://doi.org/10.1007/s12560-015-9209-1

[14] Prasanta, S.T. and Singh, O.M. (2011) Phytochemical and Pharmacological Profile of Zanthoxylum armatum DC-An Overview.

[15] Borrás-Linares, I., Fernández-Arroyo, S., Arráez-Roman, D., et al. (2015) Characterization of Phenolic Compounds, Anthocyanidin, Antioxidant and Antimicrobial Activity of 25 Varieties of Mexican Roselle (Hibiscus sabdariffa). Industrial Crops and Products, 69, 385-394. https://doi.org/10.1016/j.indcrop.2015.02.053

[16] Ali, K., Wilkes, M. and Roberts, T. (2013) Techniques for Analysis of Plant Phenolic Compounds. Molecules, 18, 2328-2375. https://doi.org/10.3390/molecules18022328

[17] Riccardo, A. and Valgimigli, L. (2012) Modulation of the Antioxidant Activity of Phenols by Non-Covalent Interactions. Organic \& Biomolecular Chemistry, 10, 4147-4158. https://doi.org/10.1039/c2ob25174d 
[18] Yao, L.H., Jiang, Y.M., Shi, J., et al. (2004) Flavonoids in Food and Their Health Benefits. Plant Foods for Human Nutrition, 59, 113-122. https://doi.org/10.1007/s11130-004-0049-7

[19] Iker, H., Alegre, L., Breusegem, F.V. and Munné-Bosch, S. (2009) How Relevant Are Flavonoids as Antioxidants in Plants? Trends in Plant Science, 14, 125-132. https://doi.org/10.1016/j.tplants.2008.12.003

[20] Miean, K.H. and Mohamed, S. (2001) Flavonoid (Myricetin, Quercetin, Kaempferol, Luteolin, and Apigenin) Content of Edible Tropical Plants. Journal of Agricultural and Food Chemistry, 49, 3106-3112. https://doi.org/10.1021/jf000892m

[21] Goldsmith, C.S. and Miller, S.E. (2009) Modern Uses of Electron Microscopy for Detection of Viruses. Clinical Microbiology Reviews, 22, 552-563. https://doi.org/10.1128/CMR.00027-09

[22] Ryu, S., You, H.J., Kim, Y.W., et al. (2015) Inactivation of Norovirus and Surrogates by Natural Phytochemicals and Bioactive Substances. Molecular Nutrition \& Food Research, 59, 65-74. https://doi.org/10.1002/mnfr.201400549

[23] Mohammad, S., Yang, S., Mizan, M.F.R., Kim, H.-S. and Ha, S.-D. (2017) Effectiveness of a Phage Cocktail as a Biocontrol Agent against L. monocytogenes Biofilms. Food Control, 7, 256-263. https://doi.org/10.1016/j.foodcont.2016.10.056

[24] Rafiq, S., Huma, N., Pasha, I., Gulzar, N., Shahid, M. and Xiao, H. (2017) Exposure of RAW-264.7 Macrophage Cell Line to Water-Soluble Extract of Cheddar Cheese: Assessment of Antioxidant Activity. JAPS: Journal of Animal \& Plant Sciences, 27, 2.

[25] Łoś, J.M., Golec, P., Węgrzyn, G., Węgrzyn, A. and Łoś, M. (2008) Simple Method for Plating Escherichia coli Bacteriophages Forming Very Small Plaques or No Plaques under Standard Conditions. Applied and Environmental Microbiology, 74, 5113-5120. https://doi.org/10.1128/AEM.00306-08

[26] Valeria, C., Andreozzi, P., D’Alicarnasso, M., et al. (2018) Broad-Spectrum NonToxic Antiviral Nanoparticles with a Virucidal Inhibition Mechanism. Nature Materials, 17, 195.

[27] Patchima, S., Michaelis, M., Schubert-Zsilavecz, M. and Cinatl, J. (2013) Differential Antiviral and Anti-Inflammatory Mechanisms of the Flavonoids Biochanin A and Baicalein in H5N1 Influenza A Virus-Infected Cells. Antiviral Research, 97, 41-48. https://doi.org/10.1016/j.antiviral.2012.10.004

[28] Jefree, J., Kianmehr, A., Mustafa, M.R., Abubakar, S. and Zandi, K. (2012) Antiviral Activity of Baicalein and Quercetin against the Japanese Encephalitis Virus. International Journal of Molecular Sciences, 13, 16785-16795.

https://doi.org/10.3390/ijms131216785 